\title{
Influence of cryomilling on structure of CoFeZrB alloy
}

\author{
J. Bednarcik ${ }^{\mathrm{a}, *}$, K. Saksl $^{\mathrm{b}}$, R. Nicula ${ }^{\mathrm{c}}$, S. Roth ${ }^{\mathrm{d}}$, H. Franz ${ }^{\mathrm{a}}$ \\ ${ }^{a}$ Deutsches Elektronen-Synchrotron (HASYLAB), Hard X-ray Diffraction Scattering, Notkestr. 85, D-22607 Hamburg, Germany \\ ${ }^{\mathrm{b}}$ Institute of Materials Research, Slovak Academy of Sciences, Watsonova 47, 04353 Košice, Slovakia \\ ${ }^{\mathrm{c}}$ EMPA, Feuerwerkerstrasse 39, $\mathrm{CH}-3602$ Thun, Switzerland \\ ${ }^{\mathrm{d}}$ IFW Dresden, Institut für Metallische Werkstoffe, Helmholtzstraße 20, D-01069 Dresden, Germany
}

\section{A R T I C L E I N F O}

Article history:

Available online 20 October 2008

\section{PACS:}

61.43.Dq

81.20.Ev

61.10.-I

77.80.Bh

Keywords:

Alloys

Synchrotron radiation

X-ray diffraction

Calorimetry

\begin{abstract}
A B S T R A C T
X-ray diffraction experiments indicate that cryomilling of an amorphous CoFeZrB alloy significantly retards mechanically-induced crystallization. After $12 \mathrm{~h}$ of milling, the samples consist mostly of an amorphous component and tiny fraction of bcc-Fe. Significant changes are observed on the radial distribution function, suggesting the reordering of atoms within the amorphous phase. Investigation of thermal stability and magnetic properties also indicate that the observed changes upon cryomilling are related to changes in the amorphous phase.
\end{abstract}

(C) 2008 Elsevier B.V. All rights reserved.

\section{Introduction}

Ball milling (BM) is a simple and versatile processing technique to synthesize nonequilibrium materials such as amorphous phases, nanocrystalline phases, and extended solid solutions [1,2]. This process has been used extensively to study the solid state amorphization of elemental powders and intermetallic compounds (see Chap. 11 of Ref. [1] and references therein). However, only a limited number of experiments were performed to explore the opposite, i.e. the crystallization of amorphous alloys induced by ball milling. For our investigations, we have chosen amorphous $\mathrm{CO}_{56}$ $\mathrm{Fe}_{16} \mathrm{Zr}_{8} \mathrm{~B}_{20}$ alloy which is known to exhibit large super-cooled liquid region and excellent soft magnetic properties, e.g. high permeability in the frequency range up to $1 \mathrm{MHz}$ [3]. In a previous work [4] we have shown that short-time BM of this alloy results in mechanically-induced crystallization. The present paper focuses on the role of the milling temperature and investigates the influence of cryomilling on the structure of the CoFeZrB metallic glass.

\section{Experimental}

Amorphous ribbons with a nominal composition $\mathrm{Co}_{56} \mathrm{Fe}_{16} \mathrm{Zr}_{8} \mathrm{~B}_{20}$ (at.\%) were prepared by single-roller melt spinning. The as-

\footnotetext{
* Corresponding author. Tel.: +49 408998 1861; fax: +49 4089944203.

E-mail address: jozef.bednarcik@desy.de (J. Bednarcik).
}

quenched ribbons were cut into small pieces and milled for $12 \mathrm{~h}$ using a RETSCH PM4000 planetary ball mill. The milling was done under argon atmosphere at a ball to powder weight ratio of $31: 1$ with a speed of $200 \mathrm{rpm}$. Hardened steel vials and balls were used. $\mathrm{BM}$ was interrupted each $30 \mathrm{~min}$ in order to cool container in a liquid nitrogen bath. Specially designed polystyrene cover was used to suppress warming up of vials during BM. High-energy X-ray diffraction (XRD) measurements were performed at the BW5 beamline of DORIS positron storage ring (Hamburg, Germany). X-ray diffraction experiments were performed in Debye-Scherrer geometry using monochromatic beam with energy of $100 \mathrm{keV}$ $(\lambda=0.12398 \AA)$. All details regarding X-ray data treating can be found elsewhere [4]. The thermal stability of the samples was examined at a heating rate of $10 \mathrm{~K} / \mathrm{min}$ by differential scanning calorimetry (DSC) using a NETZSCH DSC 404C. The thermomagnetic curves $M(T)$ were traced at $10 \mathrm{~K} / \mathrm{min}$ using a Faraday magnetic balance.

\section{Results}

The XRD patterns of ribbon and powder samples (not shown) exhibit diffuse scattering patterns typical for metallic glasses with a maximum at $q=3.05 \AA^{-1}$ and pronounced oscillations visible up to $q$ of $18 \AA^{-1}$. The corresponding structure factors, $S(q)$, and radial distribution functions, RDF, (shown in Fig. 1) were obtained from measured intensities $I(q)$ by methods described in [5]. Comparison 
of the $S(q)$ 's shape indicate slight changes due to cryomilling. Sample milled for $12 \mathrm{~h}$ shows already tiny traces of crystalline phase which could be assigned to bcc-Fe. From the type and concentration of constituent elements in $\mathrm{Co}_{56} \mathrm{Fe}_{10} \mathrm{Zr}_{8} \mathrm{~B}_{20}$ alloy it is clear that $(\mathrm{Co}, \mathrm{Fe})-\mathrm{Co}$ and $(\mathrm{Co}, \mathrm{Fe})-\mathrm{Zr}$ are the dominant atomic pairs which determine the shape of the RDF. Small but statistically significant changes are observed in the RDF's peak profile as a result of cryomilling. It is seen that the effect of cryomilling is to lower the right shoulder (position of Co-Zr bonds) while the intensity of RDF increases at the position corresponding to $\mathrm{Zr}-\mathrm{Zr}$ bonds. DSC scan of as-quenched CoFeZrB ribbon (Fig. 2) shows an endothermic event at the glass transition temperature $T_{\mathrm{g}}=839 \mathrm{~K}$, followed by a wide super-cooled liquid region $\left(\Delta T_{\mathrm{x}}=50 \mathrm{~K}\right)$ and a sharp single crystallization peak at $T_{\mathrm{x} 1}=889 \mathrm{~K}$. DSC traces of milled samples show additional exothermic peak at $T_{\mathrm{x} 2}=934 \mathrm{~K}$. The inset in Fig. 2 shows the evolution of the crystallization enthalpy $\Delta H$ of the two peaks with the onset temperatures at 889 and $934 \mathrm{~K}$, respectively. The main feature of $M(T)$ curves shown in Fig. 3 is the monotonous decrease of magnetization between 350 and $650 \mathrm{~K}$ indicating the transition of the amorphous phase from the ferromagnetic to paramagnetic state. An abrupt increase of magnetization at $900 \mathrm{~K}$ coincides with the completion of the first exothermal event as seen

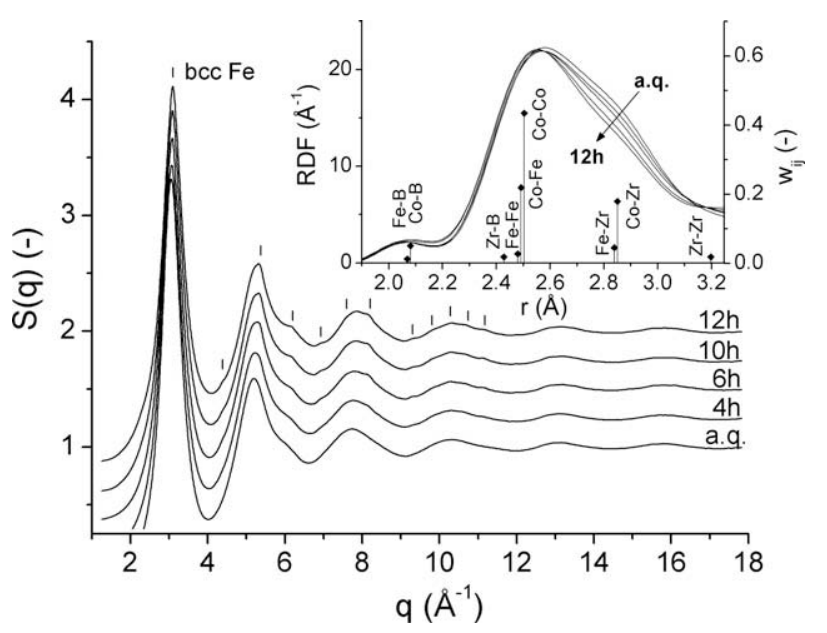

Fig. 1. Structure factor $S(q)$ of CoFeZrB as a function of milling time. The inset shows the first shell of RDF together with bond lengths (with X-ray weights $w_{i j}$ ) calculated as a sum of atomic radii.

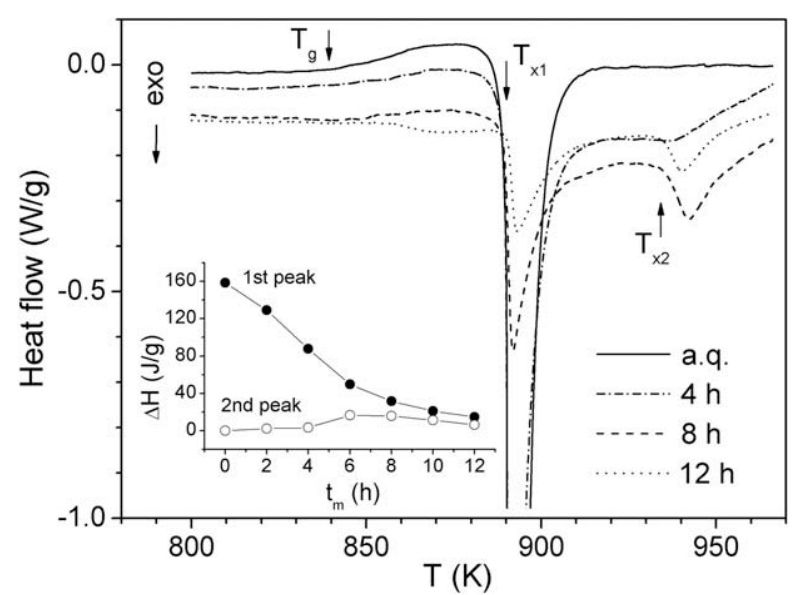

Fig. 2. DSC traces at different stages of milling. The inset shows the evolution of the crystallization enthalpy of exothermic peaks.

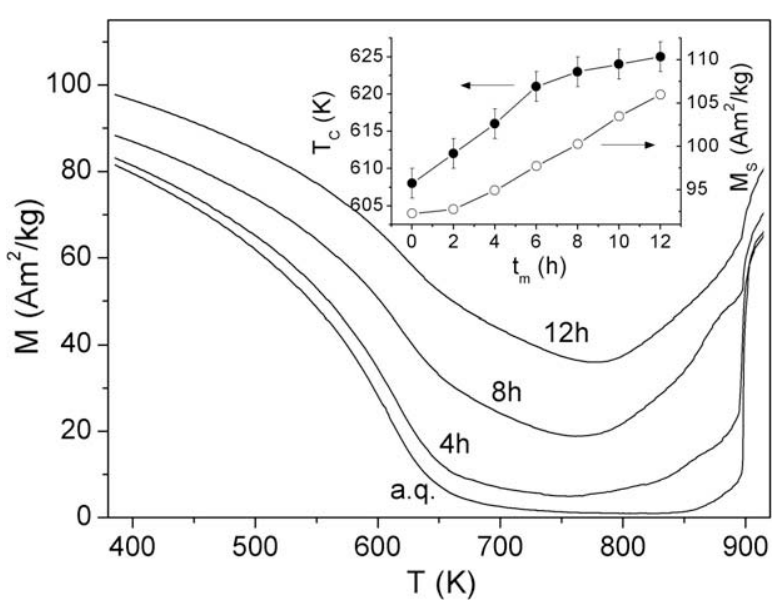

Fig. 3. Thermomagnetic curves $M(T)$ at different stages of milling. The inset shows the change of Curie temperature $T_{\mathrm{C}}$ and saturation magnetization $M_{\mathrm{S}}$ of amorphous phase with milling time $t_{\mathrm{m}}$.

from DSC. The Curie temperature of the amorphous phase $T_{\mathrm{C}}$ was inferred from the inflection point appearing on $M(T)$ curves in the range of 550-650 K. As can be seen from the inset in Fig. 3, Curie temperature $T_{\mathrm{C}}$ and saturation magnetization $M_{\mathrm{S}}$ increase after $12 \mathrm{~h}$ of milling by $17 \mathrm{~K}(\sim 2.8 \%)$ and $14 \mathrm{Am}^{2} / \mathrm{kg} \quad(\sim 15 \%)$, respectively.

\section{Discussion}

In comparison with previous studies [4] it is seen that lowering of the milling temperature (case of cryomilling) retards the mechanically-induced crystallization. After $12 \mathrm{~h}$ of milling, the sample consists mostly of an amorphous component and a tiny fraction of bcc-Fe like phase. Detailed analysis of the first coordination shell in the RDF suggests changes in the local structure of the amorphous phase. The average coordination number calculated by numerical integration of RDF between 2.6 and $3.2 \AA$ decreases by $12.4 \%$ and suggests reordering of atoms within the amorphous phase. The change of the crystallization behavior from single to two-stage and gradual vanishing of super-cooled liquid region also confirm strong impact of cryomilling on microstructure of CoFeZrB alloy. It should be noted here that similar milling done without additional cooling does not change the crystallization behavior and powders crystallize in one step [4]. Relatively steep decrease of the crystallization enthalpy together with disappearance of the super-cooled liquid region $\Delta T_{\mathrm{x}}$ during cryomilling may be related to the changes of amorphous phases, perhaps due to early stages of nanocrystallization. Also the magnetic properties, namely $T_{\mathrm{C}}$ and $M_{\mathrm{S}}$, are strongly affected by cryomilling. One could speculate that the observed behavior is mostly due to iron contamination from milling media. Inserting the values of the saturation magnetization of iron $M_{\mathrm{Fe}}=222 \mathrm{Am}^{2} / \mathrm{kg}$, of the as-quenched ribbon $M_{\mathrm{aq}}=92 \mathrm{Am}^{2} / \mathrm{kg}$, and of the observed increase of the saturation magnetization $\Delta M_{\mathrm{S}}=14 \mathrm{Am}^{2} / \mathrm{kg}$ into the equation $\Delta M_{\mathrm{S}}=$ $x_{\mathrm{Fe}} M_{\mathrm{Fe}}-x_{\mathrm{Fe}} M_{\mathrm{aq}}$, we obtain a relatively high value for the iron fraction $x_{\mathrm{Fe}}=10.8 \mathrm{wt} \%$. However, such a high amount of iron should be much better resolved by XRD. Taking into account the type of mill, speed, and duration of milling, such high value of $x_{\mathrm{Fe}}$ could not be explained in the terms of contamination by attrition. It was reported by many works that the magnitude of iron contamination of the powders milled with the steel grinding medium is in the range of $1-4 \mathrm{wt} \%$ (see Chap. 14 of Ref. [1]). One can expect that in case of cryomilling vials and balls become more brittle and thus abrasion induced change of composition may be more pronounced. 
We conclude that the observed changes in the structure, magnetic properties and thermal stability of cryomilled CoFeZrB powders may result from (i) a structural change of the amorphous phase induced by cryomilling and (ii) change in the alloy composition due to debris from the steel milling balls or vials.

\section{Conclusions}

Our studies show that cryomilling significantly retards the mechanically-induced crystallization. Only tiny traces of bcc-Fe were observed. It seems that lowering of the milling temperature restricts local temperature rises induced by BM, decreases diffusivity and thus reduces the extent of mechanically-induced crystalli- zation. Investigation of structure and magnetic properties indicate that the observed changes upon cryomilling are related to the structural changes in the amorphous phase and contamination from milling media.

\section{References}

[1] C. Suryanarayana, Prog. Mater. Sci. 46 (2001) 1.

[2] C.C. Koch, Materials Science and Technology A Comprehensive Treatment, vol. 15. VCH Verlagsgesellschaft, Weinheim, Germany, 1991. pp 193-245.

[3] A. Inoue, T. Zhang, H. Koshiba, A. Makino, J. Appl. Phys. 83 (1998) 6326.

[4] J. Bednarcik, E. Burkel, K. Saksl, P. Kollar, S. Roth, J. Appl. Phys. 100 (2006) 014903.

[5] T. Egami, S.J.L. Billinge, Underneath the Bragg Peaks: Structural analysis of Complex Materials, Pergamon Press, Elsevier, England, 2003. 